Lexis Vol. XLIII (1) 2019: 167-193

\title{
Quechuismos en la Histórica Relación del Reino de Chile de Alonso de Ovalle
}

\author{
Beatriz Gómez-Pablos \\ Universidad Comenius de Bratislava
}

\section{RESUMEN}

El presente estudio analiza las voces procedentes del quechua en la obra de Alonso de Ovalle, jesuita y cronista de Indias del siglo XVII. Aunque la Histórica Relación ha sido estudiada desde diversos puntos de vista, hasta la fecha no se ha prestado atención al aspecto lingüístico. En nuestro análisis se examina la supervivencia de dichas voces en diversas obras lexicográficas publicadas en los últimos ocho años - Academia Argentina de las Letras (2008), Álvarez Vita (2009), Asociación de Academias de la Lengua Española (2010), Academia Chilena de la Lengua (2010), Real Academia Española de la Lengua (2014), Miño-Garcés (2016), Calvo Pérez (2016)—, así como la presencia de otros americanismos.

Palabras clave: quechuismos, Alonso de Ovalle, Histórica relación del Reino Chile, americanismos

\section{Abstract}

The present study analyzes the Quechua loanwords used in the work of Alonso de Ovalle, a 17th century jesuit chronicler of the Indies. Although the Histórica Relación has been studied from different points of view, to date no attention has been paid to the linguistic aspect. The present analysis examines the survival of these words in several lexicographic works 
published in the last eight years - the Argentinian Academy of Language (2008), Álvarez Vita (2009), Association of Academies of the Spanish Language (2010), the Chilean Academy of Language (2010), the Royal Spanish Academy of Language (2014), Miño-Garcés (2016), Calvo Pérez (2016) -, as well as the presence of other Americanisms.

Keywords: Quechua loanwords, Alonso de Ovalle, Histórica Relación del Reino Chile, americanisms

\section{Introducción}

El tema de los indoamericanismos en las crónicas de Indias ha sido investigado con frecuencia por numerosos lingüistas. Son abundantes las publicaciones que extraen y analizan exhaustivamente las voces contenidas en dichas obras. No obstante, al tratarse en muchos casos de palabras que se han perdido, que estaban mal documentadas o que han alcanzado un uso geográfico reducido, la mayoría de los estudios se ocupan de ellas desde un punto de vista histórico sin establecer una relación con la actualidad. De ahí que queramos centrarnos en este último aspecto. Para ello, hemos hecho un vaciado de los americanismos que emplea Alonso de Ovalle en su crónica y los hemos distribuido según sus lenguas de origen. A continuación hemos consultado siete obras lexicográficas recientes con el fin de averiguar el uso actual de los quechuismos.

Hemos escogido la Histórica Relación por dos razones. En primer lugar, porque es una de a las menos estudiadas, al contrario de lo que sucede con la Historia natural y moral de las Indias, del jesuita José de Acosta, los Comentarios Reales y la Florida del Inca, de Garcilaso de la Vega, la Historia verdadera de la conquista de Nueva España, de Bernal Díaz del Castillo, o la Historia de las Indias y conquista de México, de Francisco López de Gómara, por nombrar apenas cinco crónicas que cuentan con una copiosísima bibliografía. Los pocos autores que han dedicado atención a la Histórica Relación del Reino de Chile se limitan a describir el contenido de la obra y presentar la biografía del autor, pero ninguno de ellos se detiene a analizar la dimensión lingüística. Aunque algunos 
estudiosos ${ }^{1}$ exaltan la crónica de Ovalle como una de las más importantes para la época colonial chilena, es escasa la atención que se le ha prestado en la investigación.

La segunda razón que nos llevó a escoger esta obra, caída en el olvido, es que los académicos del siglo XVIII no solo la mencionan en las listas de autoridades que preceden a la primera obra lexicográfica de la Real Academia Española de la Lengua, sino que hacen uso generoso de ella al citarla en los seis tomos que la componen. El cronista chileno se encuentra entre los quince primeros más citados en el Diccionario de Autoridades (1726-1739), por encima de Mateo Alemán, Góngora, Calderón y Gracián, y por debajo de Quevedo, Cervantes o Lope, entre otros (Rojo 2014, Apéndice 3). Pero antes que nada, conviene presentar brevemente al autor y su obra.

\section{Alonso de Ovalle y la Histórica Relación del Reino de Chile}

Alonso de Ovalle nació en Santiago de Chile en 1601. Fue hijo de María Pastene de Astudillo y del capitán Francisco del Manzano y Ovalle, enviado desde Buenos Aires al mando de un pelotón de soldados en 1600 . Estudió con los jesuitas en su ciudad natal y poco después en Córdoba de Tucumán. Siendo muy joven profesó en 1618 en la Compañía de Jesús. Desempeñó diversos cargos en la orden; entre otros, el de rector del Colegio de San Francisco Javier y el de procurador de la Provincia de Chile. En 1642 parte hacia España, y desde allí se dirige a Roma, donde permanece hasta 1650. Es en esa ciudad donde escribe la Histórica Relación del Reino de Chile y de las misiones y ministerios que ejercita en él la Compañía de Jesús (Roma, 1646), que poco después traducirá personalmente al italiano.

Ovalle emprende en 1650 el viaje de regreso a América y se detiene en Madrid con el fin de pedir ayuda al rey Felipe IV para los habitantes de Santiago, los cuales sufrían las consecuencias del

\footnotetext{
Bunster opina que es "la obra más valiosa de nuestra literatura colonial” (1969: 7); y lo mismo subraya Latchman que la considera "la obra cumbre de la literatura chilena del siglo XVII” (1955: 857).
} 
terremoto acaecido en 1647. Consigue permiso para que dieciséis jesuitas viajen con él y al acabar sus gestiones se embarca hacia Panamá, desde donde continúa el viaje hacia Lima. No obstante, en la capital del virreinato de Perú le acomete una fuerte fiebre que le causa la muerte y fallece en 1651, sin conseguir llegar a su tierra natal.

El jesuita chileno escribe con la intención de dar a conocer a los europeos el paisaje y la historia de su patria. De este modo su obra se inserta en el tradicional esquema de las historias naturales y morales de las Indias. En el Prólogo al lector explica los motivos que le llevaron a redactarla:

Habiendo venido del Reino de Chile y hallado en estos de Europa tan poco conocimiento del, que en muchas partes ni aun sabían su nombre, me hallé obligado a satisfacer el deseo de los que me instaron diese a conocer lo que tan digno era de saberse. Púsome esto en gran confusión, por hallarme sin materiales para el intento y tan lejos de donde pudiera haberlos para satisfacer dignamente el común deseo; pero por corresponder en alguna manera a él y a la obligación de mi oficio, y sobre todo a quien no pude dejar de obedecer, me determiné a hacer este borrón para dar alguna noticia de aquellas tan remotas regiones, si bien con temor de la nota y censura que alguno dará a esta obra de menos ajustada con las partes de una perfecta Historia, como lo confieso. Quede advertido el prudente lector, para que, reconociendo la poca comodidad y ayuda que puedo haber tenido por escribir de tan lejos como lo está Roma de Chile y tan desprevenido que ni aun intento tuve jamás de hacer esto, supla con su cordura y discreción lo que en esta obra le diere menos gusto ()$.^{2}$

A pesar de lo que afirma en el Prólogo al lector, Ovalle tuvo a su disposición algunas obras que le sirvieron de fuente, sobre todo para redactar la parte histórica. Entre las crónicas que cita destacan las Décadas de Antonio de Herrera, la Conquista de México de López de Gómara, el Nuevo descubrimiento del gran río Amazonas de Cristóbal de Acuña y los Comentarios Reales del Inca Garcilaso

2 Citamos por la edición crítica y anotada de Bunster (1969). 
de la Vega, ${ }^{3}$ además de las Cartas anuas de los jesuitas. ${ }^{4}$ Nuestro autor cita también, pero en menor medida, otros materiales como la Araucana de Alonso de Ercilla, la Historia del descubrimiento y conquista del Perú de Agustín de Zárate o la Araucana manuscrita de Hernando Álvarez de Toledo. "En efecto, en algunos capítulos, sigue a determinados autores al pie de la letra — sobre todo a Herrera, a Álvarez de Toledo y a Ercilla, por ejemplo-; y, como parecía ser costumbre en aquella época, suele incorporar a su texto, casi sin variantes y sin advertir su procedencia, pasajes enteros de otros escritores" (Bunster 1969: 9).

Más adelante, también en el Prólogo, expone la estructura de la obra y el contenido de los ocho libros de que consta:

En el primer y segundo libros, la naturaleza y propiedades de aquella tierra; en el tercero, de sus habitadores; en el cuarto y quinto, la entrada de los españoles y su conquista. En el sexto varios sucesos de la guerra, que ha ocasionado la valerosa resistencia que han hecho los araucanos a los españoles; en el séptimo los medios de paz que intentó el padre Luis de Valdivia, de la compañía de Jesús, para facilitar la predicación del santo Evangelio, y la muerte de sus dichosos compañeros; y en el último, que es el más largo de todos, el mundo que hubo de plantar la fe y los progresos que ha hecho y hace, particularmente por medio de las misiones y ministerios de nuestra Compañía.

Las dos versiones castellanas que existen son de 1646; de lo cual se deduce "que el Padre Alonso de Ovalle corrigió pliegos a medida que se iban imprimiendo" (Bunster 1969: 7). La traducción italiana, también del mismo año, está hecha a partir del texto depurado. Medio siglo más tarde, fueron vertidos al inglés los cinco primeros capítulos y publicados en Londres en $1703^{5}$ para la colección

\footnotetext{
3 “A quien en estas materias que pertenecen al Perú debemos más crédito que a otros, por haber nacido en él y sabido la lengua de los indios y haber podido por esto hacer más exacto escrutinio de todo" (lib. VIII, cap. 1 ).

4 Precisamente estas Cartas anuas, llegadas de Chile también durante su estancia en Roma, le permitieron incorporar noticias actuales a su Histórica Relación.

5 An bistorical relation of the kingdom of Chile, by Alonso de Ovalle. Translated out of Spanish, printed for A. and J. Churchill.
} 
Voyages and travels. Fuera de esto, no se conocen otras traducciones, lo cual indica la limitada recepción de que gozó la obra en el extranjero; por otro lado, escasamente difundida también en castellano. La Histórica Relación destaca además desde el punto de vista gráfico por las interesantes ilustraciones insertadas en el libro. ${ }^{6}$

El estilo de la obra es llano y ameno, con descripciones expresivas y detallistas, algunas incluso pintorescas. Ovalle no sólo es cronista de América sino que además es un cronista americano, conocedor de la realidad que le rodea. Muchos pasajes están escritos en primera persona y dan testimonio de experiencias vividas por el propio autor. Predomina la descripción de la naturaleza, mientras que los retratos psicológicos de conquistadores, militares o gobernadores brillan prácticamente por su ausencia. La identificación del autor chileno con su tierra se refleja también en el uso del lenguaje, que no renuncia al sabor localista del léxico, sobre todo a la hora de describir la fauna y la flora del país austral. Al no encontrar otros vocablos más adecuados, toma los indigenismos que conoce, añadiendo unas veces la equivalencia castellana (pampas y llanadas; parcialidades o reguas; venado o guanaco) y otras veces ofreciendo una descripción (mallcagües, que son un género de adorno que bacen para la cabeza a manera de guirnaldas, no de flores, sino de varios y finisimos colores de lanas, en que fijan unos penachos muy altos, de que usan sólo en los bailes y regocijos) o una mezcla de ambos (taltales o gallinazos, son estos casi tan grandes como patos, pero tienen mayores alas, son de color negro o pardo y voracísimos de carne en extremo). No obstante, cuando el vocablo se ha hecho familiar en el lenguaje de los españoles, se omiten la equivalencia y la descripción.

\section{Voces de origen quechua en la Histórica Relación}

La obra de Alonso de Ovalle refleja el conocimiento de numerosas palabras de origen quechua y mapuche, ${ }^{7}$ lo cual podría explicarse

\footnotetext{
Para una profundización en el tema véase Cacheda (2013).

7 Empleamos aquí mapuche y mapudungún como sinónimos.
} 
por el contacto directo con los indígenas en las misiones jesuíticas y por el estudio de sus lenguas, muy común en esa orden. Como bien se sabe, fue notable la labor realizada en este ámbito por la Compañía de Jesús en tierras americanas. Ovalle menciona la célebre obra del padre Luis de Valdivia, ${ }^{8}$ religioso que había publicado un Arte y gramática general de la lengua que corre en todo el Reino de Chile (Lima, 1606), seguido del Vocabulario de la lengua de Chile, de la Doctrina christiana y de un Confesionario breve. Un año más tarde, en 1607, imprimía en Lima su Doctrina christiana y catecismo en lengua Alletiac, que corre en la ciudad de San Juan de la Frontera, con un confesionario, Arte y Vocabulario breves. Es muy probable que Ovalle hubiese manejado esas obras.

Listamos a continuación los quechuismos encontrados en la Histórica Relación. Hemos dejado fuera de consideración los nombres de los diferentes pueblos (o naciones) indígenas y los topónimos. Junto a cada voz recogemos una breve cita ${ }^{9}$ extraída de la crónica y debajo de ella ofrecemos las definiciones de la vigésimo tercera edición del diccionario académico (DLE-2014) y del Diccionario de americanismos (DAm-2010). En caso de no haberlas encontrado en esas dos fuentes, acudimos ${ }^{10}$ al Diccionario del habla de los argentinos (DHA-2008), al Diccionario de peruanismos (DP-2009) y al Diccionario usual del español de Chile (DUECh-2010), al Diccionario del español ecuatoriano (DEE-2016) y al Diccionario de peruanismos (DiPerú-2016). Ocasionalmente añadimos un breve comentario.

(1) aillo: Y este tiene obligación de hacer fiesta el día de procesión, a los demás de su aíllo $(\mathrm{V}, 6)$

\footnotetext{
8 "Con ocasión de catequizar y hacer cristianos a unos indios que se llaman Guarpes (que son los que dijimos en su lugar, habitan en la tierra de Cuyo, que está de la otra banda de la cordillera) aprendió su lengua (que es totalmente distinta de la de Chile) y hizo gramática y vocabulario de ella y la imprimió con el de Chile, con que dejó allanado el camino a los nuestros para poder emplearse en la enseñanza y conversión de los indios" (VIII, 5).

En algunos casos hemos considerado necesario añadir algunas más.

10 Con frecuencia las definiciones son similares a las del DLE-2014 y no ha hecho falta recogerlas. Solo se ha procedido de otra manera cuando aportan alguna información nueva, pues en su mayoría se trata de diccionarios diferenciales.
} 
[a] DLE-2014: Del quechua ayllu 'familia', 'linaje', 'parcialidad'. 1. m. Chile. Cada uno de los grupos en que se divide una comunidad indígena, cuyos componentes son generalmente de un linaje.

[b] DAm-2010: (Del quechua ayllu, parentela, linaje) 1. m. Pe, Ch. Parcialidad en que se divide una comunidad indígena, cuyos componentes son generalmente de un linaje.

(2) apancora: Los cangrejos, apancoras y camarones $(\mathrm{I}, 16)$

[a] DLE-2014: 1. f. Crustáceo decápodo, braquiuro, de unos diez centímetros de longitud, con carapacho oval y espinoso y pinzas grandes y gruesas, que vive en las costas de Chile.

[b] DAm-2010: no se recoge.

[c] DP-2009: (Del quechua apancoray, cangrejo). Perú. 1. f. Cierto tipo de cangrejo marino que vive en la costa sureña.

(3) camarico: Nos salían a recebir a los caminos con camaricos (VII, 6); regalos de comestibles que se hacían a los clérigos poniéndoles sus vestidos y camarico de comida y bebida (VIII, 18)

[a] DLE-2014: De or. quechua. 1. m. Ofrenda que hacían los indios americanos a los sacerdotes, y después a los españoles.

[b] DAm-2010: 1. m. Co: SO. Obsequio, regalo.

Comentario: el DP-2009 añade además otras acepciones: 1. Primicia que el mayordomo de una hacienda enviaba al patrón. 2. (Piura) Conjunto de comestibles que se envían como obsequio a familiares o a amigos ausentes. 3. (Piura) Regalo que dan los padrinos de una boda a sus ahijados. A su vez, las definiciones del DEE-2016 aportan otros matices de interés: 1. Regalo que un campesino da su patrón o a un sacerdote, especialmente en las fiestas de carnaval. 2. Regalo que un campesino público da a un funcionario público como pago por [agilizar] un trámite.

(4) chacra:

a. Muchos lugares edificados (que allá llamamos chacras) (I, 12); llaman chacras, que son como acá las aldeas (VIII, 11); que llamamos en las Indias chacras y estancias (VIII, 26)

b. sin tener otras chácaras ni sementeras (VIII, 21) 
[a] DLE-2014: Del quechua chakra. 1. f. Arg., Bol., Ec., Par., Perú y Ur. Alquería o granja.

[b] DAm-2010: chácara. III. (del quech. chakra). 1. f. Ho: N, E, ES: $E$, Ni. Terreno de cultivo de bananos o café. 2. Gu. Terreno donde se cultivan árboles frutales.

chacra. I. (del quech. chakra). 1. f. Co:SO, Ec, Pe, Bo, Ch, $P y, A r$, $U r$. Terreno de poca extensión dedicado a la agricultura. 2. Bo: $O$, $C, S, A r, U r$. Alquería o granja.

Comentario: El cronista chileno diferencia sistemáticamente chácara 'tierra sembrada' de chacra 'aldea'. Calvo Pérez indica en su DEPP-2014 que el quechuismo chakra ('parcela de cultivo') tiene una variante frecuente con el mismo significado, chácara, consecuencia de una epéntesis. En los diccionarios consultados no hemos encontrado esta voz con el significado de 'aldea'.

(5) chañal: Los chañales, y son de manera de avellanas, aunque se diferencian en que la comida no la tienen dentro del hueso sino por de fuera (II, 6)

[a] DLE-2014: De or. quechua. 1. m. Arg., Chile y Ur. Árbol de la familia de las papilionáceas, espinoso, de corteza amarilla, y cuyas legumbres son dulces y comestibles. 2. m. Arg., Chile y Ur. Fruto del chañar.

[b] DAm-2010: (Del quech.). I. 1. m. Ch, $A r, U r$. Árbol espinoso de hojas ovaladas y corteza amarilla, similar en tamaño y forma al olivo; con su fruto se hace arrope. (Fabaceae; Geoffroea decorticans). 2. $C h, A r, U r$. Fruto dulce y comestible del chañar.

Comentario: Ambos diccionarios la recogen bajo chañar. Lüdtke (2007) opina que las voces chañar, chanal y chañaral son de posible origen quechua o cunza [atacameño]. No obstante ni el DP-2009 ni el DiPerú-2016 registran esta voz.

Respecto a la etimología de la palabra, Calvo Pérez (DEPP-2014) defiende que su origen es mapuche y que de ahí pasó al quechua: chañar. < q. chañar < ?map. chaña 'el que se desnuda' + esp. suf. rel. -ar ('árbol que pierde la corteza amarilla exterior'). NOTA: También llamado chaño (<chaña, m.), que alude a la misma planta 
conocida como Gourliea spp., Geoffroea decorticans o Lucuma spinosa.

(6) choclo: Un choclo de maíz para matar su hambre (VI, 16)

[a] DLE-2014: choclo.2. Del quechua choccllo. 1. m. Arg., Bol., Chile, Col., Ec., Par. y Perú. Mazorca tierna de maíz.

[b] DAm-2010: (Del quech. chuqllu, mazorca de maíz). 1. m. Co: O, SO, Ec, Pe, Bo, Ch, Py, Ar, Ur. Mazorca tierna de maíz. 2. Ec, Ch, Py. Maíz tierno desgranado, crudo o cocido.

(7) choros: Es también muy regalado marisco el que llaman choros (I, 16)

[a] DLE-2014: choro². Del quechua churu. 2. m. Bol. y Chile. mejillón. [b] DAm-2010: II. 1. m. Gu, Pe, Bo, Ch. Molusco bivalvo comestible, de concha oval negruzca y estriada concéntricamente en la parte exterior, y en la interior lisa y clara con visos violáceos (Mytilidae, Choromytilus chorus).

(8) cochayuyo: De estos troncos nacen unas vainas muy largas, de más de tres y cuatro varas, y algunas anchas de cuatro, seis y ocho dedos; éstas llaman cochayuyo (I, 16); encima del vestido unas yerbas de la mar, que llaman cochayuyos (VII, 5)

[a] DLE-2014: Del quechua kocha 'laguna' y yuyu 'hortaliza'. 1. m. Bol., Chile y Perú. Alga marina comestible cuyo tallo, en forma de cinta, puede alcanzar más de tres metros de longitud y $20 \mathrm{~cm}$ de anchura.

[b] DAm-2010: (Del quech. kocha, laguna, y yuyu, hierba comestible). 1. m. Pe, Bo, Chi. Alga marina cuyo tallo, en forma de cinta, puede alcanzar más de 3 metros de longitud; es comestible (Durvillaeaceae; Durvillea antárctica).

(9) cona: Aquí me tenéis, conas (llaman así a la gente de guerra) (VII, 2); Capitanes y conas (que son los soldados) (VII, 3)

[a] No se recoge en los diccionarios consultados.

Comentario: A pesar de no figurar en los diccionarios consultados, es presumible que se trate de una palabra quechua (v. yanacona). 
Febrés (1846) lo recoge en su Diccionario hispano chileno y lo define como 'mocetón: esforzado y valiente'; por lo que también se podría sostener una etimología mapuche. Frebés no menciona yanacona, solo yana que define como 'indios ladinos, criados entre españoles'.

(10) cóndor: De los que hay grandísima abundancia en las lagunas son los cóndores, blancos como armiños, de que hacen los que llaman regalillos para las manos (I, 19)

[a] DLE-2014: Del quechua cúntur. 1. m. Ave rapaz del orden de las catartiformes, la mayor de las aves que vuelan, de algo más de un metro de longitud y tres de envergadura, con la cabeza y el cuello desnudos, y en aquella carúnculas en forma de cresta y barbas, plumaje fuerte de color negro azulado, collar blanco, y blancas también la espalda y la parte superior de las alas, cola pequeña y pies negros, y que habita en los Andes.

[b] DAm-2010: No se recoge en esta acepción.

11) cumbe: hay muchos guanacos y carneros que llaman de la tierra, que son a manera de camellos, poco menores de cuya lana se hacen los cumbes (I, 5)

[a] No lo recogen el DLE-2014 ni el DAm-2010.

[b] DP-2009: cumbi. Perú. 1. m. En el Antiguo Perú, tejido muy fino, de lana de vicuña.

[c] DiPerú-2016: cumbe. m. Tela finamente tejida en la época incaica.

Comentario: José de Acosta, en su Historia natural y moral de las Indias, emplea también esta voz: "Gran suma de ropa de cumbí muy bien obrada, grande y pequeña” (citado en Alvar Ezquerra 1997, s. v. cumbi, cumbi). El DEPP-2014 ofrece una información más precisa: compi. < q. qunpi < qunpiy 'bordar delicadamente, recamar' ('uniforme militar bordado'). NOTA: De la misma etimología es cumbe 'vestido de vicuña', que se dice también cumbi y cumpi, que son meras variantes con iguales parámetros de significado y etimología.

(12) cuy: Otro género hay de conejitos semejantes a éstos, pero son domésticos y se llaman cuyes, que son también muy regalados, y de mejor vista, porque son de varios colores y manchas (I, 21) 
[a] DLE-2014: Tb. Cui, Arg., Bol., Chile y Ur. De or. quechua. 1. m. Arg., Bol., Col., Ec. y Perú. Conejillo de Indias (\| mamífero roedor). [b] DAm-2010: (Del quech. quwi). I. 1. m. Co, Ec, Pe, Bo, Ar. Conejillo de Indias más grande que el corriente, con orejas cortas, cola casi nula, tres dedos en las patas posteriores y cuatro en las anteriores (Caviidae; Cavia spp.).

(13) empacarse (de paco): Quise revolver el caballo, y para mayor dicha, se me empacó (VIII, 17)

[a] DLE-2014: De en- y paco, ${ }^{11}$ por la obstinación con que se planta este animal. 3. prnl. coloq. Arg., Bol., Chile, Ec., Par., Perú, R. Dom. y Ur. Dicho de un animal: plantarse.

[b] DAm-2010: III. 1. intr. prnl. Pe, Chi, Py, Ar, rur; Bo, pop, Ec, p.u.; rur. Detenerse un animal obstinadamente sin querer volver a ponerse en marcha.

(14) guanaco: Hay muchos guanacos y carneros que llaman de la tierra, que son a manera de camellos, poco menores de cuya lana se hacen los cumbes (I, 5); Son muy semejantes a las ovejas que dijimos de la tierra, los guanacos [...] pero diferéncianse totalmente en el color, porque el de estos es rojo, de un rubio aburelado claro y nunca se domestican (I, 21)

[a] DLE-2014: Tb. huanaco en acep. 1, Arg., Bol. y Perú. Del quechua wanaku. 1. m. y f. Mamífero camélido, propio de los Andes, muy parecido a la llama, de la cual se diferencia en ser algo mayor. U. en m. ref. a la especie.

[b] DAm-2010: (Del quech. wanaku). I. 1. m. Ec, Pe, Pe, Bo, Ch, Ar. Camélido sudamericano, de cerca de $1,5 \mathrm{~m}$ de altura hasta la cruz y poco más desde el pecho a la grupa, cabeza pequeña, orejas largas y puntiagudas, cuello largo y erguido y cuerpo cubierto de pelo largo y lustroso, de color pardo oscuro (Camelidae; Lama guanicoe).

(15) bicho: y los colchones un poco de hicho y una mala manta (VIII, 19)

11 En paco se hace referencia al origen quechua. 
[a] DLE-2014: icho. Del quechua ichu 'paja', planta gramínea. 1. m. Planta gramínea que crece en la puna.

[b] DAm-2010: icho. (Del quech. ichu). I. 1. $A r, P e, B o$, p.u. ichu. ichu. (voz quechua). I. 1. m. Pe, Bo, Ch: N, Ar: NO. Planta de hojas finas y duras; se emplea en el techado de las viviendas, como leña y para alimentar al ganado (Poaceae; Stipa ichu).

(16) buaca: En un apartamiento de los que llaman Huaca, que era lugar sagrado (VIII, 1)

[a] DLE-2014: guaca. Tb. huaca, Bol., Chile, C. Rica, Ec., El Salv., Hond., Nic., Pan., Perú y Ur. Del quechua waca 'dios de la casa'. 1. f. Sepulcro de los antiguos indios, principalmente de Bolivia y el Perú, en que se encuentran a menudo objetos de valor.

[b] DAm-2010: (Del quech. waku, dios de la casa). 3. Pe, Bo, Ch. Sepulcro indígena o de los antiguos incas en el que se hallan pertenencias de los difuntos.

(17) llanca: Échanse al cuello unas como cadenas de las que llaman llancas (III, 4)

[a] DLE-2014: Voz quechua. 2. f. Chile. Piedras pequeñas de llanca o de un mineral semejante, que usaban y usan todavía los mapuches para collares y sartas, y para adorno de sus trajes.

[b] DAm-2010: (Del quech. llanka). I. 2. Ch. Piedras pequeñas de este mismo mineral o parecidas a él, que usaban y usan todavía los mapuches para collares y sartas, y para adorno de sus trajes.

(18) lúcuma: Membrillos, que los hay como la cabeza, y otro género que llaman lúcumas, de que se hacen regaladas viandas (I, 3); lúcuma, que también la he visto en el Perú, y es muy sana y de muy buen sabor, y el hueso de dentro muy liso, de color morado $(\mathrm{V}, 10)$

[a] DLE-2014: Del quechua rucma. 1. f. Fruto del lúcumo.

Lúcumo. 1. m. Árbol originario del Perú y cultivado hoy en otros países, especialmente de la zona andina, perteneciente a la familia de las sapotáceas, de hojas casi membranáceas, trasovadas y adelgazadas hacia el pecíolo, que produce un fruto del tamaño de una manzana pequeña. 
[b] DAm-2010: I. 2. Ec, Pe, Bo: N, NE,C, Ch. Fruto de este árbol [lúcuma], de forma oblonga y piel delgada de color verde brillante antes de madurar y parda en la madurez, la pulpa, amarillo-anaranjada, es muy dulce y se emplea en la elaboración de postres y helados. (lucmo; lucma; lúcumo; lugma).

Comentario: El DiPerú-2016 reserva la forma masculina para el árbol y la femenina para su fruto: lúcuma. 2. Fruto del lúcumo, de cuerpo esférico, con cáscara delgada, verde o amarillenta, de pulpa pastosa amarilla, y con una o dos pepas marrones brillantes y redondeadas; lúcumo. m. Árbol de abundantes ramas que forman una copa esférica o cilíndrica, de hoja ancha en la punta, membranosa, de flor axilar y fruto de color verde amarillento. Calvo Pérez (DEPP-2014) explica que la etimología es aimara (lukuma), que de ahí pasó al quechua (rukma) y finalmente al español.

(19) mate: una calabaza, que llamamos mate en las Indias (III, 3)

[a] DLE-2014: Del quechua mati 'calabacita'. 2. m. Arg., Bol., Ec., Par. y Perú. Calabaza que, seca, vaciada y convenientemente abierta y cortada, sirve para muchos usos domésticos.

[b] DAm-2010: (Del quech. mati calabacita). I. 1. m. Co: SO, Pe, $B o, P y$. Vasija rústica, semiesférica, que se hace con la cáscara de algún fruto o de alguna calabaza, cortado por la mitad y vaciado.

(20) molle: Otra [bebida] hacen del que llaman huigán, y los españoles molle (I, 22)

[a] DLE-2014: Del quechua mulli. 2. m. Árbol de Bolivia, el Ecuador y el Perú, de la misma familia que el molle y cuyos frutos se emplean para fabricar una especie de chicha.

[b] DAm-2010: I. 1. m. Ec, Pe, Ch, Py, Ar, Ur. Arbusto espinoso de hasta $7 \mathrm{~m}$ de altura, con hojas simples alternas e inflorescencia en racimos (Anacardiaceae; Schinus spp).

Comentario: El DAm-2010 solo recoge la acepción de 'árbol' y la definición de molle de beber también cómo ‘árbol', pero en ningún momento menciona la bebida. 
(21) mote: Mote, que es su maíz cocido en agua simple, como el arroz en la India Oriental (III, 3)

[a] DLE-2014: Del quechua mut'i. 1. m. Maíz desgranado y cocido, sea tierno o maduro, con cáscara o pelado, que se emplea como alimento en algunas regiones de América del Sur.

[b] DAm-2010: (Del quech. mut'i). I. 1. m. Co, Ec, Pe, Bo. Maíz desgranado y cocido, sea tierno o maduro, con cáscara o pelado, que se emplea como alimento.

(22) ojota: El pie calzado con la que llaman ojota, y es a manera de alpargate (III, 4)

[a] DLE-2014: Del quechua ushuta. 1. f. Arg., Bol., Chile, Col., Ec., Par., Perú y Ur. Calzado a manera de sandalia, hecho de cuero o de filamento vegetal, que usaban los indios del Perú y de Chile, y que todavía usan los campesinos de algunas regiones de América del Sur. [b] DAm-2010: (Del quech. usuta). I. 1. f. Co, Ec, Pe, Bo, Ch, Py, Ar, Ur. Calzado tosco a manera de sandalia, hecho de cuero o de filamento vegetal, que usaban los indios del Perú y de Chile, y que todavía usan los campesinos e indígenas de algunas regiones de América del Sur.

(23) pampa: Aquel mar de tierra (que así se pueden llamar aquellas inmensas llanuras que llaman pampas) (I, 10); pampas (que son unas grandes llanadas, donde en muchas leguas no se suele topar ni un árbol ni una piedra) (II, 6)

[a] DLE-2014: Del quechua pampa 'llano, llanura'. 5. f. Cada una de las llanuras extensas de América del Sur que no tienen vegetación arbórea.

[b] DAm-2010: (Del quech. pampa, llanura). I. 1. f. Pe, Bo: C, O, Ch, Ar, Ur. Llanura extensa sin árboles.

(24) papa: El sustento de los naturales es de papas (que son unas raíces de mucha sustancia, muy comunes en todas las Indias, y allí se dan con más abundancia) (II, 1)

[a] DLE-2014: Del quechua papa. 1. f. Planta herbácea anual, de la familia de las solanáceas, originaria de América y cultivada hoy 
en casi todo el mundo, con tallos ramosos de 40 a $60 \mathrm{~cm}$ de altura, hojas desigual y profundamente partidas, flores blancas o moradas en corimbos terminales, fruto en baya carnosa, amarillenta, con muchas semillas blanquecinas, y raíces fibrosas que en sus extremos llevan gruesos tubérculos redondeados, carnosos, muy feculentos, pardos por fuera, amarillentos o rojizos por dentro y que son uno de los alimentos más útiles para el hombre. 2. f. Tubérculo de la papa. [b] DAm-2010: (De or. quech.). I. 1. f. $M x, G u, H o, E S, N i, C R, P a$, $C u, R D, P R, C o, V e, E c, P e, B o, C h, P y, A r, U r$. Tubérculo comestible de la papa, redondeado, generalmente de color pardo por fuera y blanco o amarillento por dentro. 2. $M x, H o, N i, C R, P a, C u, R D$, $P R, C o, V e, E c, P e, B o, C h, A r, U r$. Planta herbácea anual, con tallos aéreos de hasta $1 \mathrm{~m}$ de altura, raíces fibrosas y rizomas que en sus extremos desarrollan gruesos tubérculos, hojas compuestas, inflorescencia terminal, flores blancas o violáceas y fruto en baya con semillas pequeñas.

(25) poroto: Los porotos, que llamamos por otro nombre frijoles (III, 3)

[a] DLE-2014: Del quechua purutu. 1. m. Arg., Bol., Chile, Ec., Par., Perú y Ur. judía (\| planta). 2. m. Arg., Bol., Chile, Ec., Par., Perú y Ur. judía (\| semilla).

[b] DAm-2010: (Del quech. purutu). I. 1. m. Pa, Co:SO, Ec, Bo, Ch, Py, Ar, Ur. frijol.

(26) quipo: Pero suplen esta falta con sus quipos, que son unos cordeles más y menos gruesos, en que hacen variedad de ñudos, con que se entienden, para acordarse de las cosas de que han de dar razón [...]. Estos quipos son sus libros de memoria y cuentas (III, 4)

[a] DLE-2014: Del quechua quipu 'nudo'.1. m. Cada uno de los ramales de cuerdas anudados, con diversos nudos y varios colores, con que los indios del Perú suplían la falta de escritura y daban razón, así de las historias y noticias, como de las cuentas en que es necesario usar guarismos. U. m. en pl.

[b] DAm-2010: No se recoge. 
(27) quiriquincho: También se crían en las pampas y llanadas de Cuyo muchas liebres y unos que llaman quiriquinchos, cuya carne es como de lechoncillos (I, 21)

[a] DLE-2014: Del quechua quirquinchu 'armadillo'. 1. m. Arg., Bol., Chile, Ec., Perú y Ur. Mamífero, especie de armadillo, de cuyo carapacho se sirven los indios para hacer charangos.

[b] DAm-2010: No se recoge.

(28) runa: Runa, que quiere decir el que tiene entendimiento y razón

[a] DLE-2014: De or. quechua. 1. m. Hombre indio.

[b] DAm-2010: (Del quech. runa, ser humano, persona). I. 1. sust./ adj. Ec, Ar: NO, obsol; Pe, rur. Persona de raza india.

(29) tambo: Los que se llaman tambos, que corresponden a las hosterías y posadas, donde se halla lo necesario para refrescarse y para sustento de la vida; y, lo que más admira, a cada media legua se encontraban correos y postas (I, 5)

[a] DLE-2014: Del quechua tampu. 3. m. Bol. y Ec. posada (\| establecimiento de hospedaje).

[b] DAm-2010: (Del quech tampu, casa posada). I. 1. m. Ec, Pe, Bo: $O$. Venta o posada.

(30) topo: Préndela a los hombros con unos punzones de plata (que llaman topos) (III, 4)

[a] DLE-2014: Del quechua tири 'prendedor'. 1. m. Arg., Bol., Chile, Ec. y Perú. Prendedor tradicional indígena, en forma de alfiler grande, rematado en una cuchara o disco con grabados regionales. [b] DAm-2010: I. 1. m. Ec, Pe, Bo, Ch, Ar: NO. Prendedor tradicional indígena, en forma de alfiler grande, rematado en una cuchara o disco con grabados regionales.

(31) vicuña: cabras monteses que llaman vicuñas, y tienen una lana tan fina y delicada (I, 5); Preciosas lanas de vicuña y ovejas de la tierra (IV, 2)

[a] DLE-2014: Del quechua vicunna. 1. f. Mamífero camélido del tamaño del macho cabrío, al cual se asemeja en la configuración general, pero con cuello más largo y erguido, cabeza más redonda 
y sin cuernos, orejas puntiagudas y derechas y piernas muy largas, que tiene un pelaje largo y finísimo de color amarillento rojizo, y vive salvaje en manadas en los Andes del Perú y de Bolivia. 2. f. Lana de la vicuña. 3. f. Tejido que se hace de la lana de la vicuña.

[b] DAm-2010: ${ }^{12}$ I. 1. f. Co, Ec, Pe, Bo, Ch. Mamífero rumiante de hasta $80 \mathrm{~cm}$ de longitud, que se asemeja al macho cabrío, pero con el cuello más largo y erguido y la cabeza más redonda y sin cuernos, orejas puntiagudas y piernas muy largas; tiene un pelo largo y finísimo de color amarillento rojizo en el lomo y blanco en el vientre y las patas (Camelidae; Vicugna vicugna).

(32) viracocha: los españoles, los llamaron Viracochas, que quiere decir gente que aportó por el mar o espuma del mar $(\mathrm{V}, 16)$

[a] DLE-2014: Del quechua firakocha, nombre de un dios de la mitología incaica. 1. m. Entre los súbditos de los incas, conquistador español.

[b] DAm-2010: I. 1. sust./adj. Pe: S. Persona de raza blanca. rur; pop.

(33) yanacona: Eran los yanaconas, entre los indios, cierto linaje de gente sujeta a perpetua servidumbre [...]. Lo que en Chile significa ahora el nombre de yanacona no es otra cosa que los indios que no son de encomienda (IV, 16); yanaconas, que son los indios de servicio (VIII, 15)

[a] DLE-2014: Del quechua yanakuna. 1. adj. Dicho de un indio: Que estaba al servicio personal de los españoles en algunos países de la América meridional. U. t. c. s.

[b] DAm-2010: (Del quech. yanakuna, criado). I. 1. m-f. Pe; sust./ adj. $E c, B o, A r$. Indio que es aparcero en el cultivo de una tierra.

Comentario: Sobre el origen de esta voz remitimos al artículo de Cerrón-Palomino (2007) quien hace un profundo y pormenorizado estudio de dicha palabra y afirma en él que el uso de yanacona comienza a ser obsoleto, fuera de su sentido histórico: "El vocablo,

12 El DAm-2010 recoge la etimología bajo wicuña (voz quechua). 
por lo demás, de cuyo uso ampliamente extendido dan cuenta los trabajos lexicográficos modernos citados, parece haber entrado en una fase de obsolescencia, al haberse quebrado el aparato estructural agrario de corte latifundista que lo nutría. Ello es cierto con respecto a la acepción general y moderna de la palabra, porque en su sentido de categoría socioeconómica incaica, más restringido, seguirá vigente como otros tantos términos propios de la civilización del Tahuantinsuyo" (2007: 165).

(34) zapallo: los zapallos, que decimos calabazas en España (III, 3) [a] DLE-2014: Del quechua sapallu. 2. m. Arg., Bol., Chile, Col., Ec., Hond., Par., Perú y Ur. Calabaza comestible.

[b] DAm-2010: (Del quech. sapallu, calabaza). I. 1. m. Ho, CR, Pa, $\mathrm{Co}: \mathrm{SO}, \mathrm{Ve}: \mathrm{O}, \mathrm{Ec}, \mathrm{Pe}, \mathrm{Bo}, \mathrm{Ch}, \mathrm{Ar}, \mathrm{Ur}$. Fruto del zapallo, de forma generalmente oblonga, lisa y dura, de color verde con pintas claras y carne amarilla; es comestible. 2. $\mathrm{Ho}, \mathrm{CR}, \mathrm{Pa}$, Co: SO, Ve:O, Ec, $B o, C h, P y, A r, U r$. Planta herbácea rastrera, de fruto comestible, con tallos huecos, rugosos y provistos de zarcillos, hojas grandes, enteras y lobuladas, y flores amarillas. (Curcubitaceae; Cucurbita máxima).

\section{Otros americanismos presentes en la obra}

Además de los quechuismos, la crónica de Alonso de Ovalle contiene cinco nahuatlismos (aguacate, camote, chilacayote, chile, pitahaya), dieciocho voces de las lenguas antillanas (aji, anones, cacique, cacicazgo, canoa, caoba, embijado (de bija), guanábana, guayaba, guayacán, jagüeyes, macana, ${ }^{13}$ maíz, mamey, manglares, papaya, piragua, pitabaya) y cuatro voces del cuna, aimara, cumanagoto y tupí-guaraní (chicha, amauta, micos, tucán, respectivamente). Cuando el autor jesuita desconoce la denominación, se limita a describir el objeto; como sucede por ejemplo con el pecarí:14 "Entre

\footnotetext{
13 El DUECh-2010 sostiene que el origen de macana es quechua.

14 La entrada del DAm-2010 es la siguiente: (Del guar.). I. 1. m. $M x, C o, E c, P e, B o$, Py, Ar. Ur. Mamífero artiodáctilo de hasta $50 \mathrm{~cm}$ de altura, parecido al jabalí europeo
} 
otras, es notable una cierta especie de puercos, que andan en muchas manadas, los cuales tienen el ombligo en el espinazo" (I, 5). ${ }^{15}$

Las palabras que Ovalle emplea con mayor frecuencia son: maíz, cacique y canoa; seguidas de chacra, chicha, maloca, pampa, regua y yanacona. El resto de las voces solo se registra normalmente una vez. La Histórica Relación contiene también indoamericanismos cuya lengua de origen es incierta. Es el caso de cibil, ${ }^{16}$ cipizapote, ${ }^{17}$ cocobolo, dante [danta], rubul, tacum y tiburón. Predominan, sin embargo, las de origen quechua (véase arriba) y mapuche (carén, chavalongo, choñi, culén, degu, buigán, leupe, loica, loco, luche, machi, madi, malal, malcagüe, maloca, maloquear, mañegue, maque, patagua, pеиси [penco], pingueda, quelu [quilo], quinchamali, regua [rehue], taca, taltal, toque [toqui], toqui, ullpu [ulpo], ulmen, últe $u$ [builte], uñi). Los 104 indoamericanismos (cuatro de ellos derivados: cacicazgo, embijado, empacarse y maloquear) presentes en la crónica se distribuyen, según su origen:

pero sin cola, de cerdas largas y fuertes, colmillos pequeños y una glándula en la parte superior de lomo que segrega una sustancia fétida; su carne y piel son muy apreciadas (Tayassuidae; Tayassu spp.).

15 El Diccionario de Autoridades lo recoge bajo saíno.

16 No lo recogen nuestros diccionarios, pero sí aparece en otras crónicas de Indias, como por ejemplo en la Descripción Corographica del terreno, ríos, árboles y animales de las dilatadissimas Provincias del gran Chaco, Gualamba: $y$ de los ritos, y costumbres de las innumerables naciones bárbaras, e infieles, que la habitan... (Córdoba [de Tucumán], 1733), de Pedro Lozano, donde se lee: “El Cibil es árbol muy grande, fortísimo especialmente en las quebradas, que tira siempre a buscar el sol. Su corteza es admirable para curtir" (apartado IV, sobre la Calidad de la Tierra del Chaco, árboles, y plantas, que produce).

17 Amado Alonso apunta que se trata de "una fruta americana que se llama zapotillo o chicozapote. Tirso la llama cipizapote (La villana de Vallecas). Nuestro llorado Pedro Henríquez Ureña me decía que el nombre hubo de aprenderlo Tirso en Santo Domingo, a principios del siglo XVII. Pero este caso apenas entra en nuestras series. Tanto lo de chico-zapote (cf. zapotillo) como lo de cipi-zapote son versiones castellanizadas del náhuatl tzictzápotl, análisis o etimologías populares apoyadas en chico o en cipi-zape" (1947: 11, n. 16). Mientras que, por su parte, Prieto García-Seco, refiriéndose al Diccionario de la lengua española (1917) de José Alemany y Bolufer, escribe: “Allí se registra la voz cipizapote, con la marca fest.[ivo] y con remisión a zapote. Se trata de una creación ocasional, una deformación léxica que solo se registra en la comedia de Tirso de Molina La villana de Vallecas” (2007: 132). Llama la atención que Ovalle recogiese esta extraña voz en su Histórica Relación. 
Indoamericanismos según origen

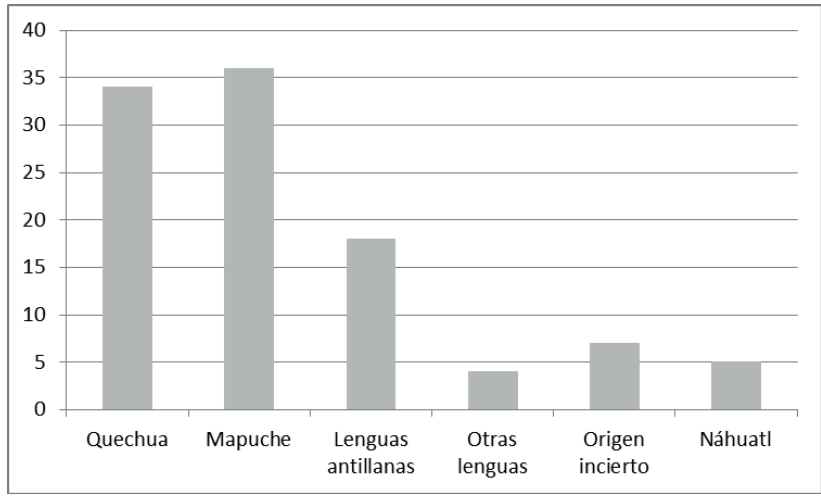

\section{A modo de conclusión}

De modo general, puede afirmarse que los 34 quechuismos que recoge Ovalle en su crónica tienen vigencia en el español actual, si incluimos en el concepto de vigencia las voces que hacen referencia a realidades pasadas y que algunos lingüistas llaman voces históricas. Todos los quechuismos, con excepción de cumbe y cona, se recogen en el DLE-2014, la mayoría de ellos con una indicación etimológica sobre su origen quechua. ${ }^{18} \mathrm{El} \mathrm{DAm}-2010$ no registra cóndor, cumbe, quipo ni quirquincho. Como es sabido, esta obra suele omitir las palabras que pertenecen al español genera ${ }^{19} \mathrm{y}$ las voces históricas en caso de no haber adoptado un significado nuevo en la actualidad.

La mitad de los quechuismos pertenecen a los campos de la fauna y la flora, mientras que los demás están relacionados sobre todo con aspectos socioculturales que se enraízan en la cultura indígena: organización social (aíllo), religiosidad (buacas), indumentaria y adornos (llanca, ojota, topo), artesanía (cumbe), gastronomía (molle, mote), ocupaciones (conas, yanaconas), agricultura (chacra),

\footnotetext{
18 No entramos ahora en la transcripción del quechua, diferente en cada diccionario.

19 Aunque en ese caso siempre se escapa alguna voz como por ejemplo tucán, que sí se incluye.
} 
contabilidad (quipo), etc. Al tratarse de realidades con una larga tradición histórica y tener en muchos casos conexión con el imperio incaico, algunos diccionarios emplean marcas diacrónicas como bistórico, para subrayar que forman parte del pasado, o usan el pretérito imperfecto o expresiones referidas a los incas en el cuerpo de la definición: 'ofrenda que hacían los indios' (camarico), 'En el antiguo Perú' (cumbe), 'sepulcro indígena o de los antiguos incas' (buaca), 'los indios del Perú suplían [...] y daban razón' (quipo), 'que estaba al servicio personal de los españoles' (yanacona); si bien, otras veces se indica que 'usaban y todavía usan' los indígenas (llanca, ojota). Respecto al tipo de palabra, cabe decir que en las 34 voces analizadas aparece un único verbo (empacarse), mientras que el resto - como suele suceder- son sustantivos. En cuanto a la ortografía, existen ligeras variaciones en algunas palabras: aíllo/ ayllo, cuy/cuis, ${ }^{20}$ buaca/guaca, icho/ichu, quipo/quipu, etc.

Es cierto y conocido, que las marcas diatópicas que brindan las obras lexicográficas a veces denotan imprecisión. Esto se debe a que escasean los atlas lingüísticos, a que no se cuenta aún con diccionarios de todas las regiones del continente americano y a que faltan estudios sobre el léxico de algunos países. Aun así y teniendo en cuenta las marcas geográficas, ${ }^{21}$ podemos distribuir el uso de estos quechuismos en cuatro grupos: a) los que se usan en el español general (cóndor, mate, pampa, etc.), b) los compartidos por varios países (choclo, poroto, zapallo, etc.), c) los restringidos a un solo país y d) los que se refieren a realidades históricas (cona, yanacona, quipo, etc.). Respecto al punto c), nos limitamos a exponer un ejemplo, donde se percibe con claridad la imprecisión de las marcas diatópicas. La voz camarico aparece sin marca en el DLE-2014 y con una única marca Co: SO en el DAm-2010. No obstante, al contrastar la información con otros diccionarios, descubrimos que también se usa en Ecuador (DEE-2016) y Perú

\footnotetext{
20 Forma generalizada en Argentina (DHA-2008).

21 Para algunas palabras el DLE-2014 no ofrece marca diatópica en su primera acepción, mientras que el DAm-2010 sí lo hace (icho, mate, molle, mote, pampa, papa, poroto runa, vicuña, yanacona).
} 
(DP-2009). ${ }^{22}$ Teniendo esto en cuenta, hemos confirmado que en nuestro listado de voces no se halla ninguna propia de un solo país.

Llamativa es la ausencia de la palabra cona en los diccionarios consultados, pues - como ya se dijo- no se recoge en ninguno de ellos. También es quizás la más conflictiva a la hora de precisar su etimología. No obstante, nos parece justificable apostar por el origen quechua. Si yanacon $a^{23}$ es el indio de servicio, macacona es el agricultor de macas u hoyas excavadas en la arena en la zona costera $^{24}$ y mamaconas son las mujeres que trabajaban en los templos y se encargan de educar a las vírgenes del sol, es probable que la voz cona esté emparentada con estas. Por otro lado, es cierto que autores como Zapater hablan de los conas como guerreros, ${ }^{25}$ pero lo hacen en el contexto de la cultura mapuche, asociados a los ulmenes y los toquis (1997: 450). Las definiciones ofrecidas por el DHA2008, el DP-2009, el DUECh-2010 o el DEE-2016 sobre voces pertenecientes a la fauna y la flora suelen ser casi siempre extensas. En algún que otro caso, quizás demasiado extensa si se considera que es un objeto conocido por todos los hablantes (v. papa en el DAm-2010).

También resulta interesante observar el cambio semántico que han experimentado algunas de estas palabras y que ha contribuido a un aumento de la polisemia. Vayan algunos ejemplos:

papa: Agujero en una media o calcetín, particularmente en el talón (DAm-2010, DHA-2008).

tambo: Establecimiento ganadero destinado al ordeño de vacas y a la venta de su leche DAm-2010, DHA-2008).

viracocha: persona de raza blanca (DAm-2010), huiracocha: hombre de tez blanca (DEE-2016).

zapallo: Cabeza de una persona (DAm-2010, DHA-2008).

\footnotetext{
22 El DiPerú-2016 recoge una acepción diferente: 'trabajo de sustitución que se hace al ausente en la mita'.

23 Matallana (2013) presenta anacona como sinónimo o variante de este vocablo.

24 Véase Busto (1981: 108).

25 Zapater (1997), a su vez, recoge muchas de sus informaciones de la Historia General del Reyno de Chile. Flandes Indiano (1674), del jesuita Diego de Rosales.
} 
Finalmente cabe resaltar la formación de palabras derivadas: chacra $>$ chacarear, chacareria, chacarero, chacarilla; chañar $>$ chanaral; empacarse > empaque; pampa $>$ pampeano, pampero; poroto $>$ porotada, porotazo, porotero, porotito; tambo > tambero; zapallo $>$ zapallazo, entre otras. ${ }^{26} \mathrm{~A}$ veces se trata de usos metafóricos, como sucede por ejemplo con zapallazo, 'golazo' (DHA-2008), o porotazo, 'gran acierto en un juego de azar o en una empresa arriesgada' (DUECh-2010).

Por todo lo aquí expuesto, se deduce que los quechuismos recogidos por el cronista Alonso de Ovalle en su Histórica Relación del Reino de Chile, no solo han pervivido hasta la fecha, sino que gozan de total vitalidad.

\section{Referencias bibliográficas}

\section{Academia Argentina de Letras}

2008 Diccionario del habla de los argentinos (DHA-2008). Buenos Aires: Emecé.

Academia Chilena de la Lengua

2010 Diccionario de uso del español de Chile (DUECh-2010). Santiago de Chile: MN Editorial.

Alonso, Amado

1947 “Trueques de sibilantes en antiguo español”. Nueva Revista de Filología Hispánica, 1, 1, 1-12.

Alvar EzQuerra, Manuel

1997 Vocabulario de indigenismos en las crónicas de Indias. Madrid: CSIC.

Álvarez Vita, Juan

2009 Diccionario de Peruanismos. El habla castellana del Perú (DP2009). Lima: Universidad Alas Peruanas.

Asociación de Academias de la Lengua Española

2010 Diccionario de americanismos (DAm-2010). Madrid: Santillana.

26 Véase en DHA-2008, DP-2009, DUECh-2010, DEE-2016, DiPerú-2016. 
Bunster, César

1969 "Algo acerca del trabajo realizado y algunas reflexiones sobre el valor literario de la obra”, en Ovalle, 7-23.

Busto, José Antonio del

1981 Perú incaico. Lima: Librería Studium.

Cacheda, Rosa Margarita

2013 "El Reino de Chile y las imágenes de la Histórica Relación de Alonso de Ovalle. Una aproximación a las crónicas de Indias". Boletín del Seminario de Estudios de Arte y Arqueología. 79, 203-226.

Calvo Pérez, Julio

2014 Diccionario etimológico de palabras del Perú (DEPP-2014). Lima: Universidad Ricardo Palma.

Calvo Pérez, Julio (dir. )

2016 Diccionario de Peruanismos (DiPerú-2016). Lima: Buenaventura-Academia Peruana de la Lengua.

Cerrón-Palomino, Rodolfo

2007 "Yanacona". Boletín de la Academia Peruana de la Lengua. 43, 149-169.

Corominas, Joan y José Antonio Pascual

1980-1991 Diccionario crítico etimológico castellano e bispánico (DCECH). Madrid: Gredos.

Esteve Barba, Francisco

1992 Historiografía indiana. Madrid: Gredos.

FEBRÉs, Andrés

1846 Diccionario hispano chileno, enriquecido y mejorado por el RP. Misionero Fr. Antonio Hernández. Santiago de Chile: Imprenta de los tribunales.

Gútemberg BoHórquez, Jesús

1984 Concepto de 'americanismo' en la historia del español. Punto de vista lexicológico y lexicográfico. Bogotá: Instituto Caro y Cuervo.

HANISH, Walter

1976 El historiador Alonso de Ovalle. Caracas: Universidad Católica Andrés Bello. 
LATCHAM, Ricardo A.

1955 "Un clásico colonial: El Padre Alonso de Ovalle". Revista Bolivar, 45, 853-864.

Lira Urquieta, Pedro

1944 El Padre Alonso de Ovalle. El hombre, la obra. Santiago de Chile: Difusión Chilena.

LozAno, Pedro

1733 Descripción chorográphica del terreno, ríos, árboles y animales de las dilatadissimas Provincias del gran Chaco. Córdoba de Tucumán: Colegio de la Assumpcion.

LÜDTKE, Jens

2007 "Las corrientes de la hispanización lingüística de Hispanoamérica” En Actas del XV Congreso de la Asociación Internacional de Hispanistas. Vol. 1. Eds., Beatriz Mariscal y Aurelio González. México D. F.: Fondo de Cultura Económica, 123-147.

Matallana Peláez, Susana

2013 "Yanaconas: indios conquistadores y colonizadores de Nuevo Reino de Granada, siglo XVI". Fronteras de la historia. 18, 2, 21-45. https://doi.org/10.22380/2027468837

MiÑo-Garcés, Fernando

2016 Diccionario del español ecuatoriano (DEE-2016). Quito: Pontificia Universidad de Ecuador.

Ovalle, Alonso de

[1646] Histórica Relación del Reino de Chile y de las misiones y 1969 ministerios que ejercita en él la Compañia de Jesús. Santiago de Chile: Instituto de Literatura Chilena.

Prieto García Seco, David

2007 "Notas sobre el Diccionario de la lengua (1917) de José Alemany y Bolufer”. Revista de Lexicografía. 13, 125-138.

Real Academia Española

[1726-1739] 1963 Diccionario de Autoridades. Madrid: Gredos.

2014 Diccionario de la lengua española (DLE-2014). Madrid: Espasa Calpe.

Rojo, Guillermo

2014 "Análisis cuantitativo de las citas del Diccionario de Autoridades”. Boletín de la Real Academia Española, 94, 137-196. 
VALDIVIA, Luis de

[1606]1887 Arte, Vocabulario y Confesionario de la lengua de Chile. Leipzig: Teubner.

VIAL, Gonzalo

2009 Chile. Cinco siglos de historia. Tomo 1. Santiago: Zig-Zag.

Zamora Munné, Juan Clemente

1976 Indigenismos en la lengua de los conquistadores. San Juan de Puerto Rico: Editorial Universitaria.

Zamora Vicente, Alonso

2015 La Real Academia Española. Madrid: Fundación María Cristina Masaveu Peterson.

ZAPATER, Horacio

1997 "Huincas y mapuches (1550-1662)”. Historia. 30, 441-504.

Recepción: 31/05/2017

Aceptación: 6/11/2018 